\author{
(D) Pınar Küçükdemirci Kaya, \\ (1) Halil Erkan Sayan, \\ (D) Murad Kaya, \\ (1) Nermin Kelebek Girgin
}

\section{Are the Tidal Volumes Used in Intensive Care Units Suitable for Lung Protective Ventilation? Can Training Ensure Compatibility?}

\author{
Yoğun Bakımda Kullandığımız Tidal Volümler Koruyucu \\ Akciğer Ventilasyonuna Uygun mu? Eğitim ile \\ Uygunluk Sağlanabilir mi?
}

Gelis Tarihi/Received : 20.12 .2018

Kabul Tarihi/Accepted : 20.08.2019

(CTelif Hakkı 2019 Türk Yoğun Bakım Derneği Türk Yoğun Bakım Dergisi, Galenos Yayınevi tarafından yayınlanmıștır.
Pınar Küçükdemirci Kaya

Nermin Kelebek Girgin

Bursa Uludağ Üniversitesi Tıp Fakültesi, Anesteziyoloji ve Reanimasyon Anabilim Dalı, Yoğun Bakım Bilim Dalı, Bursa, Türkiye

Halil Erkan Sayan

Sağlık Bilimleri Üniversitesi, Bursa Yüksek Ihtisas Eğitim ve Araştırma Hastanesi, Anesteziyoloji ve Reanimasyon Kliniği, Bursa, Türkiye

\section{Murad Kaya}

Sağlık Bakanlığı Bursa Devlet Hastanesi, Bursa, Türkiye

Dr. Pınar Küçükdemirci Kaya (凶), Bursa Uludağ Üniversitesi Tıp Fakültesi, Anesteziyoloji ve Reanimasyon Anabilim Dalı, Yoğun Bakım Bilim Dalı, Bursa, Türkiye

E-posta : pinark.kaya@yahoo.com

Tel. : : : +90533 5545080

ORCID ID : orcid.org/0000-0002-8428-8245

Sunulduğu Kongre:19.Ulusal Yoğun Bakım Kongresi, 19-22 Nisan 2018-Antalya'da e-poster olarak sunulmuştur.
ÖZ Amaç: Günümüzde invaziv mekanik ventilasyonla(IMV) ilişkili akciğer hasarını önlemek için düşük tidal volüm(VT) ile koruyucu akciğer ventilasyonu(KAV) önerilmektedir. Çalışmamızda IMV uygulanan kritik hastalarda VT/ideal vücut ağırlığı(IVA) değerlerinin KAV için önerilen değerlere(6-8 $\mathrm{mL} / \mathrm{kg}$ ) uygun olup olmadığını, yüksek VT uygulanma riski olan hastaları, KAV ilkeleri ile ilgili bilgilendirme ve uygulanan kısa bir testin KAV'a uygun IMV'ye katkısının olup olmadığını bulmayı amaçladık.

Gereç ve Yöntem: Çalışmamız Bursa'daki 3 hastanenin yoğun bakımında nokta-prevalans çalışması olarak planlandı. IMV uygulanan, 18 yaşından büyük ve ARDS tanısı olmayan hastalar çalıșmaya alındı. Hastaların demografik verileri ve IMV parametreleri kaydedildi. Takiben IMV parametrelerini ayarlayan hekimlere KAV ilkelerini içeren bir test yapıldı ve IVA'ya göre uygulanması gereken VT değerleri gösterildi. 24 saat sonra ventilatör parametreleri tekrar kaydedildi. Vücut kitle indeksleri(VKI), uygulanan ortalama tidalvolüm [VTort=dakikavolümü=MV/Solunumsayısı(RR)] ve IVA'ya göre Vort.(Vort/IVA) değerleri hesaplandı.

Bulgular: Çalışmaya 56 hasta alındı. Hastalar $65.43 \pm 18.87$ (ort. \pm SD) yaşında olup \%58.9 ( $n=33)^{\prime} u$ erkekti. Vücut kitle indeksleri $27.84 \pm 7.0$ olan hastalarda en sık kullanılan ventilasyon modu SIMV(\% 75) idi. Ortalama VT:549.32 $\pm 151.00 \mathrm{~mL}(9.31 \pm 3.07 \mathrm{~mL} / \mathrm{kgIVA})$ saptandı. Vort/IVA'ya göre kadın cinsiyet $(10.77 \pm 2.74 \mathrm{~mL} / \mathrm{kg})$ ve $\mathrm{VKI} \geq 30(10.82 \pm 3.80 \mathrm{~mL} / \mathrm{kg})$ olmasının erkek $(8.31 \pm 2.91 \mathrm{~mL} /$ $\mathrm{kg})$ ve $\mathrm{VKI}<30(8.67 \pm 2.47 \mathrm{~mL} / \mathrm{kg})$ olmasına göre yüksek $V T$ ile ventilasyon için risk faktörü olduğu belirlendi (sırasıyla $p=0.002, p=0.015$ ). Illk ölçümlerden sonra KAV ilkelerinin sorulduğu testin uygulanmasını ve IVA'ya göre uygulanması gereken VT değerlerinin gösterilmesini takiben yapılan 2. ölçümde VTort./IVA $(8.81 \pm 3.49 \mathrm{~mL} / \mathrm{kg}$ )'ların anlamlı olarak düştüğü saptandı(p=0.026).

Sonuç: Çalışmamızda VTort/IVA değerlerinin, KAV için önerilen 6-8mL/kg'ın üzerinde olduğu saptandı. Kadın ve $\mathrm{VKI} \geq 30$ olan hastaların yüksek VT ventilasyonu ile ilișkili olduğu, IMV parametrelerini ayarlayan hekimlere KAV ilkelerini içeren bir değerlendirme testinin yapılmasının ve IVA'ya göre uygulanması gereken $\mathrm{VT}$ değerlerinin gösterilmesinin $\mathrm{KAV}$ 'a uygun $\mathrm{VT}^{\prime}$ ler ile ventile edilen hasta sayısını artırdığı görüldü.

Anahtar Kelimeler: Koruyucu akciğer ventilasyonu, kritik hasta, mekanik ventilasyon, yoğun bakım

ABSTRACT Objective: Low tidal volume (VT) and lung protective ventilation (LPV) are recommended to prevent lung injury associated with invasive mechanical ventilation (IMV). Present study aimed to determine the patients with risk of high VT application, whether VT calculated according ideal body weight (IBW) values are suitable for the recommended $(6-8 \mathrm{~mL} / \mathrm{kg})$ and whether a questionnaire on the issue contributes to IMV suitable for LPV.

Materials and Methods: Present study is conducted as a multicenter point - prevalence study in the intensive care units of three hospitals in Bursa. Non-ARDS patients receiving IMV and patients who were older than 18 years were included in the study. IMV parameters and demographic data of the patients were collected. Then, the physicians responsible of ventilatory management completed a questionnaire about LPV strategies and VT values required according to the IVA were shown. 
After 24 hours, mechanical ventilation parameters were re-collected. Body mass index (BMI), average tidal volume applied [VTmean=minute volume (VE)/ Respiratory rate (RR)] and VTmean for IBW (VTmean/IBW) values were calculated.

Results: Fifty-six patients were included in the study. There were 33 male patients (58.9\%) and the mean age of the patients was $65.43 \pm 18.87$ years. The mean BMI of the patients was $27.84 \pm 7.0$. The most commonly used ventilation mode was SIMV (75\%). The VTmean was $549.32 \pm 151.00 \mathrm{~mL}$ (VTmean/ $\mid \mathrm{BW}=9.31 \pm 3.07 \mathrm{~mL} / \mathrm{kg})$. According to VTmean/IBW, for the use of large VTs, being female $(10.77 \pm 2.74 \mathrm{~mL} / \mathrm{kg})$ and having $B M \mid \geq 30(10.82 \pm 3.80 \mathrm{~mL} / \mathrm{kg})$ posed significantly higher risk than being male $(8.31 \pm 2.91 \mathrm{~mL} / \mathrm{kg})$ and having $\mathrm{BMl}<30(8.67 \pm 2.47 \mathrm{~mL} / \mathrm{kg})(\mathrm{p}=0.002, \mathrm{p}=0.015$ respectively). The results showed a significant decrease $(\mathrm{p}=0.026)$ in $\mathrm{VTmean} / \mathrm{BBW}(8.81 \pm 3.49 \mathrm{~mL} / \mathrm{kg})$ values after the physicians completed LPV questionnaire and were shown the VT values (predicted by IBW).

Conclusion: In our study, VTmean/IBW values were found to be higher than 6-8 $\mathrm{mL} / \mathrm{kg}$, the recommended value for LPV. Ventilation with high VT was associated with female gender and having a BMI of $\geq 30$. Completing the LPV questionnaire and seeing the VT values (predicted by IBW) contributed to the number of the patients ventilated with VT values suitable LPV.

Keywords: Lung protective ventilation, critically ill patient, mechanical ventilation, intensive care unit

\section{Giriş}

Son yıllarda invaziv mekanik ventilasyon (IMV) tedavisinin, daha önce hasarlanmış veya hasarlanmamış normal akciğere zarar verebileceği gösterilmiştir. Bu hasar patolojik olarak inflamatuar hücre infiltratları, hyalin membranlar, pulmoner vasküler permeabilite artışı ve pulmoner ödem ile karakterizedir (1). IMV'nin pulmoner etkileri, ventilatör ile ilişkili akciğer hasarı (VILI: ventilator-induced lung injury) olarak adlandırılır $(1,2)$.

Koruyucu akciğer ventilasyonunun (KAV) özellikle de düşük VT'nin VILI'yı azaltarak sağ kalımı artırdığı ortaya konmuş ve akut solunum sıkıntısı sendromu (ARDS) olan hastalarda standart tedavi haline gelmiştir (2). Günümüzde ARDS tanısı olmayan kritik hastalarda ve genel anestezi ile opere edilen hastalarda düşük VT'nin konvansiyonel VT'ye göre potansiyel faydaları araştııımaktadır. Yapılan bir çalışmada ideal vücut ağırlığına (IVA) göre $6 \mathrm{~mL} / \mathrm{kg}$ ile ventile edilen kritik hastalar, $10 \mathrm{~mL} / \mathrm{kg}$ ile ventile edilenlerle karşılaştırımış ve düşük VT ile ventile edilenlerde plazma sitokin düzeyleri belirgin olarak düşük bulunmuştur. Yazarlar, düşük VT ile ventile edilenlerde ARDS gelişme insidansının daha az olacağını ileri sürmüşlerdir (3). ARDS tanısı olmayan kritik hastaların alındığı başka bir çalışmada da ilk 48 saat yüksek VT uygulanmasının pulmoner komplikasyonlar ile ilişkili olduğu saptanmıştır (4). Kritik hastalarda VILI'nın IMV tedavisinin hangi aşamasında başladığı ve hastaların ne kadarında oluştuğu da araştııımış ve tıbbi kayıtlarında herhangi bir akciğer hasarı olmayanların \%24'ünde 5 günlük IMV tedavisi sonunda VILI geliştiği gözlenmiştir. Yazarlar ayrıca yüksek VT ( $>6 \mathrm{~mL} / \mathrm{kg} I V A)$, kan ürünü transfüzyonu ve asideminin $(\mathrm{pH}<7.35) \mathrm{VILI}$ için risk faktörü olduğunu ileri sürmüşlerdir (5).

VILI'yi önlemek amacıyla IMV tedavisi uygulanacak hastalarda KAV ilkelerine uygun tidal volüm ayarlanması ARDS hastalarında olduğu kadar, günlerce hatta aylarca IMV tedavisine intiyacı olan kritik hastalarda da önemlidir. ARDS hastalarında ve anestezi verilen hastalarda düşük tidal volüm uygulanırlığının sorgulandığı birçok çalışma $(2,6-8)$ mevcut olmasına rağmen, ARDS tanısı olmayan kritik hastaların bu ilkelere uygun olarak ventile edilip edilmediğini sorgulayan yeterli çalışma yoktur.

Bu çalışmada ARDS tanısı olmayan ve IMV tedavisi uygulanan kritik hastalarda, VT/IVA değerlerinin KAV için önerilen değerlere $(6-8 \mathrm{~mL} / \mathrm{kg})$ uygun olup olmadığını, yüksek VT uygulanma riski olan hastaları, KAV ilkeleri ile ilgili bilgilendirme ve uygulanan kısa bir testin KAV'a uygun IMV'ye katkııının olup olmadığını araştırmayı amaçladık.

\section{Gereç ve Yöntem}

Çalışmamız Bursa il merkezindeki 3 hastanenin 3.basamak erişkin yoğun bakımında (YB) nokta-prevalans çalışması olarak planlandı. Etik kurul onayı alınarak (No:2011KAEK-25 2018/06-32) YB'de IMV uygulanan hastaların aynı gün demografik verileri (yaş, cinsiyet, boy, kilo), yatış tanıları, akut fizyoloji ve kronik sağlık değerlendirme (APACHE) II skorları, solunum ara yüzleri (entübasyon tüpü, trakeostomi kanülü), ventilatördeki gün sayıları ve ventilatör parametreleri [ventilasyon modu, mevcut tidal volüm, dakika volümü, solunum sayısı, pozitif soluk sonu basıncı-PEEP ve tepe inspiratuar basınç-(PIP)] kaydedildi. Çalışmaya katılan hastanelerde kullanılan mekanik ventilatör cihazlarının teknik özellikleri nedeniyle, her hastada Pplato basıncı ölçülemedi. Bu nedenle çalışmamızda Pplato yerine PIP değeri kullanıldı. 18 yaşından küçük ve ARDS tanılı hastalar çalışmaya alınmadı.

Hastaların ideal vücut ağırlıkları (IVA) [Erkek:50+0.91 (Boy152.4), Kadın:45.5+0.91 (Boy-152.4)] ve vücut kitle indeksleri (VKI: vücut ağılığı/boy²) hesaplandı. Mekanik ventilasyonda 
uygulanan dakika volümü $\left(V_{E}\right)$, solunum sayısına $(R R)$ bölünerek ortalama $V T\left(V T o r t=V_{E} / R R\right)$ bulundu. Ideal vücut ağırlığına göre VTort (VTort/IVA) değerleri de hesaplandı.

Takiben IMV parametrelerini ayarlayan hekimlere KAV ilkelerini içeren bir test yapıldı (Tablo 1). Ayrıca görsel olarak kadın ve erkek için boy ve ideal vücut ağırlığına göre KAV'a uygun tidal volümlerin (VT/IVA:6-7-8 ml/kg) tabloları gösterildi (Tablo 2) (9).

24 saat sonra aynı hastaların ventilatör parametreleri tekrar kaydedildi. Uygulanan VTort. ve IVA'ya göre Vort. değerleri yeniden hesaplandı. Hastalarda uygulanan IMV'de KAV'a uygunluk [IVA'ya göre tidal volümler $(6-8 \mathrm{~mL} / \mathrm{kg})$ ] değerlendirildi.

\begin{tabular}{|c|c|c|c|c|c|}
\hline Sorular & A & B & $\mathrm{C}$ & D & $E^{*}$ \\
\hline KAV stratejilerine uygun olması için $\mathrm{P}_{\text {PLATO }}<$ kaç $\mathrm{cmH}_{2} \mathrm{O}^{\prime}$ nun altında olmalıdır? & 30 & 40 & 50 & 25 & - \\
\hline $\begin{array}{l}\text { iMV tedavisi yapılan hastanın VT değeri ayarlanır iken hastaya ait hangi veri } \\
\text { kullanılır? }\end{array}$ & $\begin{array}{l}\text { Güncel } \\
\text { vücut } \\
\text { ağırlığı }\end{array}$ & $\begin{array}{l}\text { İdeal } \\
\text { boy }\end{array}$ & $\begin{array}{l}\text { İdeal } \\
\text { vücut } \\
\text { ağırlığı }\end{array}$ & VKi & - \\
\hline IVA, hastaya ait hangi demografik veriye göre hesaplanır? & $\begin{array}{l}\text { Boy } \\
\text { Cinsiyet }\end{array}$ & $\begin{array}{l}\text { Boy } \\
\text { Yaş }\end{array}$ & $\begin{array}{l}\text { Boy } \\
\text { Vücut } \\
\text { ağırlığı }\end{array}$ & $\begin{array}{l}\text { Vücut } \\
\text { ağırlığı } \\
\text { Yaş }\end{array}$ & - \\
\hline $\begin{array}{l}\text { KAV stratejilerine göre ARDS olmayan hastalarda ayarlanan VT, iVA'ya göre } \\
\text { hangi aralıkta olmalıdır? (mL) }\end{array}$ & $6-8$ & $8-10$ & $12-14$ & $16-18$ & - \\
\hline
\end{tabular}

\begin{tabular}{|l|l|l|l|l|}
\hline $\begin{array}{l}\text { Tablo 2 ideal vücut ağırlığına göre kadınlarda ve erkeklerde } \\
\text { hesaplanan tidal volümler }\end{array}$ \\
\hline \multicolumn{5}{|l|}{ Erkekler için iVA'ya göre hesaplan VT'ler } \\
\hline Boy/cm & iVA & $6 \mathrm{~mL} / \mathrm{kg}$ & $7 \mathrm{~mL} / \mathrm{kg}$ & $8 \mathrm{~mL} / \mathrm{kg}$ \\
\hline 147 & 45,4 & 272 & 318 & 363 \\
\hline 150 & 47,7 & 286 & 334 & 382 \\
\hline 152 & 50 & 300 & 350 & 400 \\
\hline 155 & 52,3 & 314 & 366 & 418 \\
\hline 157 & 54,6 & 328 & 382 & 437 \\
\hline 160 & 56,9 & 341 & 398 & 455 \\
\hline 163 & 59,2 & 355 & 414 & 474 \\
\hline 165 & 61,5 & 369 & 431 & 492 \\
\hline 168 & 63,8 & 383 & 447 & 510 \\
\hline 170 & 66,1 & 397 & 463 & 529 \\
\hline 173 & 68,4 & 410 & 479 & 547 \\
\hline 175 & 70,7 & 424 & 495 & 566 \\
\hline 178 & 73 & 438 & 511 & 584 \\
\hline 180 & 75,3 & 452 & 527 & 602 \\
\hline 183 & 77.6 & 466 & 543 & 621 \\
\hline 185 & 79,9 & 479 & 559 & 639 \\
\hline 188 & 82,2 & 493 & 575 & 658 \\
\hline 190 & 84,5 & 507 & 592 & 694 \\
\hline & & & & \\
\hline
\end{tabular}

\begin{tabular}{|c|c|c|c|c|}
\hline \multicolumn{5}{|c|}{ Kadınlar için iVA'ya göre hesaplanan VT'ler } \\
\hline Boy $/ \mathrm{cm}$ & iVA & $6 \mathrm{~mL} / \mathrm{kg}$ & $7 \mathrm{~mL} / \mathrm{kg}$ & $8 \mathrm{~mL} / \mathrm{kg}$ \\
\hline 147 & 40,9 & 245 & 286 & 327 \\
\hline 150 & 43,2 & 259 & 302 & 346 \\
\hline 152 & 45,5 & 273 & 319 & 364 \\
\hline 155 & 47,8 & 287 & 335 & 382 \\
\hline 157 & 50,1 & 301 & 351 & 401 \\
\hline 160 & 52,4 & 314 & 367 & 419 \\
\hline 163 & 54,7 & 328 & 383 & 438 \\
\hline 165 & 57 & 342 & 399 & 456 \\
\hline 168 & 59,3 & 356 & 415 & 474 \\
\hline 170 & 61,6 & 370 & 431 & 493 \\
\hline 173 & 63,9 & 383 & 447 & 511 \\
\hline 175 & 66,2 & 397 & 463 & 530 \\
\hline 178 & 68,5 & 411 & 480 & 548 \\
\hline 180 & 70,8 & 425 & 496 & 566 \\
\hline 183 & 73,1 & 439 & 512 & 585 \\
\hline 185 & 75,4 & 452 & 528 & 603 \\
\hline 188 & 77,7 & 466 & 544 & 622 \\
\hline 190 & 80 & 480 & 560 & 640 \\
\hline
\end{tabular}




\section{İstatistiksel değerlendirme}

Çalışmanın analizleri SPSS 20.0 programında yapıldı. Sonuçlar yüzde ve ortalama standart sapma (SD) olarak verildi. Gruplar arasındaki karşılaştırmalarda ki kare ve T test kullanıldı. $\mathrm{P} \leq 0.05$ istatistiksel olarak anlamlı kabul edildi.

\section{Bulgular}

Çalışmaya 60 hasta alındı. Ikinci ölçüm sırasında ventilatör tedavisi sonlanmış 4 hasta çalışma dışı bırakıldı. Kalan 56 hasta $65.43 \pm 18.87$ yaşında, \%58.9 (n=33)'u erkek ve VKI'leri $27.84 \pm 7.0$ idi. APACHE II skorları $24 \pm 6.57$ olan hastaların \%57.1 ( $n=32)^{\prime}$ i orotrakeal entübe, \%42.9 $(\mathrm{n}=24)^{\prime} \mathrm{u}$ trakeostomiliydi. IMV modları \%75 senkronize aralıklı zorunlu ventilasyon (SIMV) ve \%25 basınç destekli ventilasyon (PSV) olarak ayarlanmıştı. Hastalarda ortalama VTort:549.32 $\pm 151.00 \mathrm{~mL}$, PEEP:6.30 $1.66 \mathrm{cmH} 2 \mathrm{O}$, PIP:24.80 $\pm 6.21 \mathrm{cmH} 2 \mathrm{O}$ saptandı (Tablo 3).

Hastalar $9.31 \pm 3.07 \mathrm{~mL} / \mathrm{kglVA}$ ile ventile edilmekteydi. Kadınların VTort./IVA'ları $(10.77 \pm 2.74 \mathrm{~mL} / \mathrm{kg} I V A)$

\begin{tabular}{|c|c|}
\hline \multicolumn{2}{|c|}{$\begin{array}{l}\text { Tablo 3. Hastaların demografik verileri, yatış tanıları ve invaziv } \\
\text { mekanik ventilasyon parametreleri }\end{array}$} \\
\hline Cinsiyet (K/E) (n) (\%) & $23 / 33(41.1 / 58.9)$ \\
\hline Yaş (yıl) (Ort_SD) & $65.42 \pm 18.87$ \\
\hline VKi (Ort $\pm S D)$ & $27.84 \pm 7.00$ \\
\hline APACHE II skoru (Ort $\pm S D)$ & $24 \pm 6.57$ \\
\hline \multicolumn{2}{|l|}{ Yatış Tanısı (n) } \\
\hline TIkayıcı-kanayıcı SVO & 13 \\
\hline Pnömoni & 14 \\
\hline Sepsis & 4 \\
\hline $\mathrm{KOAH}$ & 9 \\
\hline KRY & 3 \\
\hline Travma & 3 \\
\hline Diğer & 10 \\
\hline \multicolumn{2}{|l|}{ iMV parametreleri } \\
\hline PIP $\left(\mathrm{cm} \mathrm{H}_{2} \mathrm{O}\right)(\mathrm{Ort} \pm \mathrm{SD})$ & $24.80 \pm 6.21$ \\
\hline PEEP $\left(\mathrm{cm} \mathrm{H}_{2} \mathrm{O}\right)(\mathrm{Ort} \pm \mathrm{SD})$ & $6.30 \pm 1.66$ \\
\hline PSV (\%) & 25 \\
\hline SIMV (\%) & 75 \\
\hline \multicolumn{2}{|c|}{$\begin{array}{l}\text { K: Kadın, E: Erkek, VKi: Vücut kitle indeksi, APACHE: Akut fizyoloji ve kronik sağlık } \\
\text { değerlendirmesi, SVO: Serebrovasküler hastalık, KOAH: Kronik obstruktif akciğer } \\
\text { hastalığı, } \\
\text { KRY: Kronik renalyetmezlik, iMV: Invaziv mekanik ventilasyon, PIP: Tepe inspiratuar } \\
\text { basınç, PEEP: Pozitif ekspirasyom sonu basınç, PSV: Basınç destekli ventilasyon, } \\
\text { SIMV: Senkronize aralıklı zorunlu ventilasyon. }\end{array}$} \\
\hline
\end{tabular}

erkeklerinkinden $(8.31 \pm 2.91 \mathrm{~mL} / \mathrm{kglVA})$ yüksekti $(p=0.002)$.

$V K I \geq 30 \quad(n: 17)$ olan hastaların VTort./IVA değerleri $(10.82 \pm 3.80 \mathrm{~mL} / \mathrm{kgIVA}), \mathrm{VK} \mid<30$ (n:39) olanlardan $(8.67 \pm 2.47$ $\mathrm{mL} / \mathrm{kglVA}$ ) anlamlı olarak yüksek saptandı ( $p=0.015)$.

Illk ölçümlerden sonra ventilasyon parametrelerini ayarlayan hekimlere KAV ilkelerinin sorulduğu testin uygulanmasını ve görsel olarak ideal vücut ağırlığına göre VT'lerin gösterilmesini takiben 2.gün yapılan ölçümde tüm hastalarda VTort./IVA $(8.81 \pm 3.49 \mathrm{~mL} / \mathrm{kg})^{\prime}$ larının ilk günkü ölçüme $(9.31 \pm 3.07 \mathrm{~mL} / \mathrm{kg})$ göre anlamlı olarak düştüğü görüldü( $p=0.026)$. Bu ölçümde de kadınlar $(10 \pm 3.25 \mathrm{~mL} / \mathrm{kg})$ erkeklere $(7.72 \pm 3.27 \mathrm{~mL} / \mathrm{kg})$ göre anlamlı olarak daha yüksek volümlerle ventile edilmekte idi $(p=0.05)$.

Kadınların ortalama tepe inspiratuar basınçları erkeklerinkinden her iki ölçümde de daha yüksek olmasına rağmen, bu fark istatistiksel olarak anlamlı değildi (Tablo 4).

Vort./IVA'da ilk ölçüm ve 2. Ölçümdeki sonuçlar karşılaştırıldığında düşüş oranlarında cinsiyete ve VKI'ye göre istatiksel anlamlı farklılık saptanmadı. Ikinci ölçümde $V K \mid<30$ olanların Vort/IVA'ları düşerken VKI $\geq 30$ olanların Vort/IVA'ları yükselmiş idi. Ölçümlerin sonuçları cinsiyet ve VKI'ye göre $(V K \mid<30, V K I \geq 30)$ Şekil 1 ve 2 'de görülmektedir.

\begin{tabular}{|l|l|l|}
\hline \multicolumn{3}{|l|}{ Tablo 4. Cinsiyete göre havayolu basınç değerleri } \\
\hline Değişkenler & PIPort1 (ort $\pm S D)$ & PIPort2 (ort $\pm S D)$ \\
\hline Tüm hastalar & $24.80 \pm 6.21$ & $25.41 \pm 6.92$ \\
\hline Erkek & $23.87 \pm 6.01$ & $23.72 \pm 6.34$ \\
\hline Kadın & $26.13 \pm 6.37$ & $27.82 \pm 7.13$ \\
\hline
\end{tabular}

PIPort1: ilk ölçümde hesaplanan ortalama tepe inspiratuar basınç, PIPort2: ikinci ölçümde hesaplanan ortalama tepe inspiratuar basınç

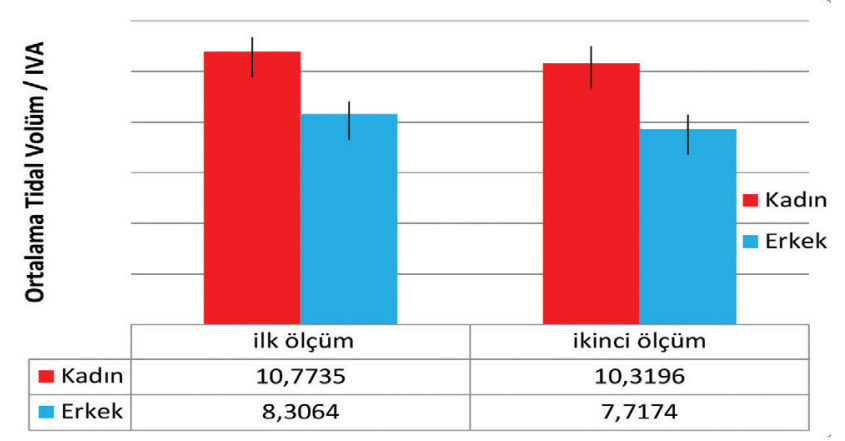

Şekil 1. Illk ölçüm ve ikinci ölçüm sonrası kadın ve erkeklerin ortalama tidal volüm/iVA değerleri

Vort/ivA: Ortalama tidal volüm/ideal vücut ağırlığı.

illk ölçüm Vort./ivA, kadın-erkek, $p=0.002$

ikinci ölçüm Vort./IVA, kadın-erkek, $p=0.05$

illk-ikinci ölçüm her iki cinsiyet için $p=0.026$ 


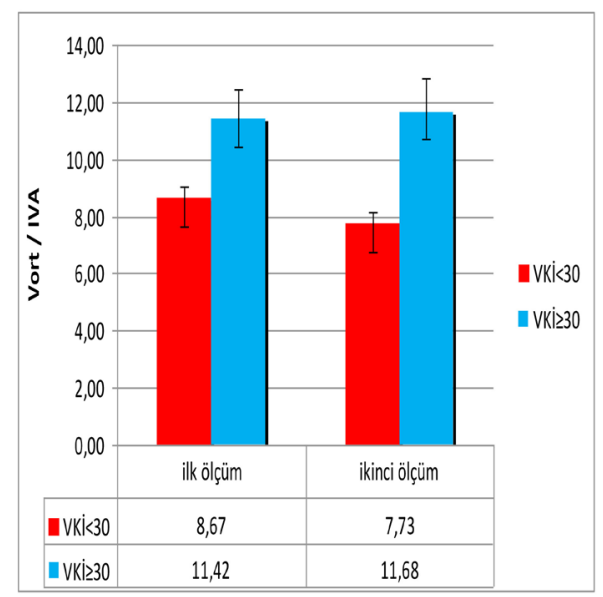

Şekil 2. Illk ölçüm ve ikinci ölçüm sonrası VKi³30 ve VKi<30 olanlarda ortalama tidal volüm/IVA değerleri

Vort/iVA: Ortalama tidal volüm/ideal vücut ağırlığı.

ilkk ölçüm Vort./IVA, VKi<30 ve VKỉ30, $p=0.015$

Illk-ikinci ölçüm tüm hastalar için $\mathrm{p}=0.0 .26$

\section{Tartışma}

Invaziv mekanik ventilasyon uygulanan kritik hastalarda KAV uygulanırlığını, mekanik ventilasyonu ayarlayan hekimlere KAV ile ilgili kısa bir test yapılmasının ve ideal vücut ağırlığına göre kadın ve erkekte uygulanması gereken VT'lerin gösterilmesinin KAV uygulanırlığına etkisini araştırdığımız çalışmamızda; VT/IVA değerlerinin KAV için önerilen (6-8 $\mathrm{mL} / \mathrm{kg}$ ) değerlerden yüksek olduğunu, özellikle kadın ve VKI $\geq 30$ olan hastaların IVA'ya göre $8 \mathrm{~mL} / \mathrm{kg}^{\prime}$ dan daha fazla volümle ventile edildiğini, KAV ile ilgili değerlendirme testinin uygulanmasından sonra VT değerlerinin düşerek KAV için önerilen değerlere yaklaştı̆̆ını ve KAV'a uygun olarak ventile edilen hasta sayısının arttığını saptadık.

Bilgimiz dahilinde ARDS tanısı olmayan kritik hastalarda KAV stratejilerinin uygulanırlı̆ını araştıran ve bu konudaki bilgilendirmenin KAV uygulanırlığına etkisini araştırmaya yönelik nokta prevelans çalışması bulunmamaktadır. Ülkemizde YB'lerde binlerce hastaya IMV tedavisi uygulanmakta fakat bu hastalarda gelişen VILI insidansı bilinmemektedir. Iyatrojenik bir komplikasyon olan VILI'ye neden olmak ya da VILI oluşumunu önlemek ventilasyon parametrelerini ayarlayan hekimin sorumluluğundadır. ARDS dışı nedenlerden dolayı IMV tedavisi uygulanan kritik hastalarda kullanılacak uygun tidal volüm değeri kesin olmamakla birlikte birçok çalışmada düşük tidal volüm (6-8 mL/kglVA) uygulanarak VILI riskinin azaltılabileceği gösterilmiştir (3-5). Yapılan bir metanalizde 15 randomize ve
5 gözlemsel çalışma incelenmiş, ARDS tanısı bulunmayan 2822 hastada yüksek veya düşük tidal volüm ile ventile edilenler karşılaştııılmış ve düşük tidal volüm uygulananlarda daha az akciğer hasarı ve daha düşük mortalite oranı saptanmıştır (10).

KAV'ın uygulanırlığını sorgulayan veya faydalarını araştıran çalışmalarda hasta grubu olarak daha çok ARDS hastaları ve genel anestezi altındaki hastalar seçilmiştir. Genel anestezi uygulanan hastalarda KAV ilkelerinin konvansiyonel yöntemlerle karşılaştıııldığı birçok çalışma mevcuttur (6-8). Abdominal cerrahi uygulanan hastalarda yapılan randomize kontrollü bir çalışmada peroperatif konvansiyonel mekanik ventilasyon uygulanan grup (10-12 mL/kglVA, PEEP:0 $\mathrm{cmH} 2 \mathrm{O}$ ) ile KAV uygulanan grup (6-8 mL/kgIVA, PEEP:6-8 $\mathrm{CmH}_{2} \mathrm{O}$ ) karşılaştııılmış ve KAV uygulanan grupta postoperatif 7.gün akciğer ve akciğer dışı komplikasyonların daha düşük olduğu saptanmıştır. Bu çalışmanın sonunda peroperatif 6-8 mL/kgIVA ile ventile edilen hastalarda, postoperatif komplikasyonların daha az görüldüğü bildirilmiştir (6).

Son dönemde kritik hastalarda yapılmış iki büyük çalışmanın sonuçları ise çelişkilidir. Bu çalışmaların ilkinde 2184 kritik hasta, uygulanan tidal volüme göre 3 gruba ( $<7 \mathrm{~mL} / \mathrm{kg} / \mathrm{IVA}, 7-10 \mathrm{~mL} / \mathrm{kg} / \mathrm{IVA},>10 \mathrm{~mL} / \mathrm{kg} / \mathrm{IVA})$ ayrılmış ve düşük tidal volüm ile ventile edilen grupta ARDS ve pnömoni oranı belirgin olarak düşük saptanmıştır. Pulmoner komplikasyonların azalmasının YB'de yatış süresini ve hastanede kalış süresini kısalttığı, 28.gün sağkalımı arttırdığı ve mortalitenin azaldığı bildirilmiştir (4). Ikinci büyük çalışma olan PRoVENT çalışmasında ise pulmoner komplikasyonlar ile düşük tidal volüm ventilasyonu arasında herhangi bir ilişki bulunamamıştır (11). Bu iki çalışmayı karşılaştıran editöryal bir yazıda ise kesin yargılara varmak için daha fazla çalışmaya intiyaç olduğu belirtilmiştir (12). Bizim çalışmamızda bu çalışmalardaki gibi kritik hastalarda yapıldı ancak KAV'a uygun olmayan mekanik ventilasyonun pulmoner komplikasyonlarla ilişkisi veya mortaliteye etkisi araştırılmadı. Ayrıca çalışmamızdaki hastalar diğer iki çalışmadaki hastalara göre daha ileri yaşta, APACHE II skorları daha yüksek ve mekanik ventilasyon süreleri daha uzundu.

Günümüzde genel kanı VILI'yı azaltmak için KAV ilkelerine uygun mekanik ventilasyon uygulanması yönündedir. Ancak YB'lerde mekanik ventilatör ayarları yapılırken KAV ilkelerine dikkat edilip edilmediğini, hangi hasta gruplarında IVA'ya göre yüksek tidal volümler uygulandığını bilmemekteyiz. $\mathrm{Bu}$ konudaki çalışmalar çeşitli ventilasyon modlarında solutulan hastalarda standardizasyonun yapılamamasından 
kaynaklanan metadolojik çelişkiler nedeniyle çoğunlukla genel anestezi alan ve zorunlu soluklarla ventile edilen hasta gruplarında yapılmış olup hastaların cinsiyet ve/veya VKI'lerine göre farklı sonuçlar elde edilmiştir. Avustralya'da genel anestezi uygulanan 272 hastada yapılan prospektif bir çalışmada ortanca tidal volüm $9.7 \mathrm{~mL} / \mathrm{kg} I V A$ ve PEEP değerleri $5 \mathrm{cmH} 2 \mathrm{O}$ bulunurken erkeklerin IVA'ya göre daha yüksek volümlerle ventile edildiği saptanmıştır (7). Yine peroperatif 2960 hasta ile yapılan çok merkezli bir çalıșmada kadınların ve obez hastaların IVA'ya göre daha yüksek tidal volümlerle ventile edildiği bulunmuştur (8). Bizim çalışmamızda da kadınlar erkeklere, $V K I \geq 30 \mathrm{~kg} / \mathrm{m}^{2}$ olanlar ise $\mathrm{VKI}<30 \mathrm{~kg} / \mathrm{m}^{2}$ olanlara göre belirgin olarak daha yüksek VT/ IVA ile ventile edilmekte idi. Mekanik ventilatör kullanıcılarının ideal vücut ağırlığını dikkate almadan, tidal volümü güncel vücut ağırlığına göre ayarlamalarının bu sonuca yol açmış olabileceğini düşünmekteyiz.

Çalışmamız kritik hastalarda yapılan diğer çalışmalar $(4,11)$ gibi farklı ventilasyon modlarında (PSV, SIMV) solutulan hastalarda yapıldı. Farklı dinamiklere sahip solutma şekillerinde standardizasyonu sağlayabilmek amacıyla dakika volümü, hastanın toplamda aldığı soluk sayısına bölünerek ortalama bir değer elde edildi. Bu değerin zorunlu soluklarla ventile edilen hastadaki gibi kesin sonuçlar içermemesi nedeniyle, bu değerin kullanıımasının çalıșmamızın en önemli sınırlaması olduğunu düşünmekteyiz.

Yapılan bir araştırma, YB hekimlerinin bir günde tek bir hastanın tedavisi hakkında 80-200 arasında karar vermek zorunda olduklarını göstermiştir (13). Bu kararlardan biri de IMV uygulananlarda KAV'a uygun tidal volümün belirlenmesidir. Bizim çalıșmamız ve güncel çalışmalar göz önünde bulundurulduğunda bu uygulamayı günlük YB pratiğinde doğru olarak yapamadığımız ve bu konuda gerek bilgi eksikliği gerekse farkındalığımızın yeterli olmadığı ortadadır. Ingiltere'de yapılan prospektif gözlemsel bir çalışmada mekanik ventilatörlere $8 \mathrm{~mL} / \mathrm{kg} I V A$ hedef tidal volüm konmuş, böylece tidal volüm fazla ayarlandığında cihazın alarm vermesi ile hedeflenen tidal volüm değerlerinin KAV'a uygun olması sağlanmıştır (14).

Statik inspiratuar basıncın (plato basıncı) $30 \mathrm{cmH}_{2} \mathrm{O}$ altında olması ve IVA'ya göre uygun VT $(6-8 \mathrm{ml} / \mathrm{kg})$ uygulanması ile KAV'a uygunluğun değerlendirilmesini planladığımız çalışmamızda, 3 hastanede bulunan mekanik ventilatör cihazlarının teknik özelliklerinin farklı olması nedeniyle hastaların hepsinde plato basınçları ölçülemedi ve tepe inspiratuar basınçlar kaydedildi. Plato basınçları ölçülememesine rağmen, tepe inspiratuar basınçların ortalamasının $30 \mathrm{cmH}_{2} \mathrm{O}^{\prime}$ dan düşük olduğu ve cinsiyete göre anlamlı bir fark olmadığı saptandı. Tidal volümlerin IVA'ya göre değil güncel vücut ağırlığına göre ayarlandığı hipotezi ile yaptığımız bu çalışma sonucunda, ne yazık ki düşüncemizin doğru olduğunu göstermiş olduk. Bu çalışmada mekanik ventilasyon kullanan yoğun bakım hekimlerine bu konuda küçük bir test yaparak ve görsel olarak da uygun tidal volümleri gösterek KAV'a uygun volümleri elde etmeyi amaçladık. Çalıșmayı etkileyen birçok unsur bir yana bırakıldığında çalışmamızın en önemli sonucu; test yapılmadan ve görsel olarak uygun VT'ler gösterilmeden önce IMV uygulanan kritik hastalardaki TV'lerin KAV için önerilen 6-8 mL/kgIVA'nın üzerinde olduğunun saptanması, özellikle kadınlar ve VKI $\geq 30$ olan hastaların gereğinden yüksek tidal volümler ile ventile edilmesi idi. KAV ile ilgili değerlendirme testi yapıp, görsel olarak KAV'a uygun $V^{\prime} T^{\prime}$ leri gösterdikten sonra yaptığımız ikinci değerlendirmede ise uygulanan ortalama tidal volüm değerleri anlamlı olarak düşmekle birlikte $V K I \geq 30$ olan hastalara uygulanan $\mathrm{VT}^{\prime}$ lerin düşürülmediği görüldü.

Sonuç olarak; hastaların IVA'ları dikkate alınarak IMV ayarlarının yapılmasının, kadın ve obez hastalarda VT hedeflerinde daha dikkatli olunmasının ve YB hekimlerinin KAV ilkeleri hakkında bilgilendirilmesinin KAV'a uygun $\mathrm{VT}^{\prime}$ 'ler ile mekanik ventilasyon uygulanmasının sağlanmasında etkili olabileceği kanısındayız. 


\section{Kaynaklar}

1. Slutsky AS, Ranieri VM. Ventilatorinduced lung injury. N Engl J Med 2013;369:2126-36

2. Acute Respiratory Distress Syndrome Netwok, Brower RG, Matthay MA, Schoenfeld D, Thompson BT, Wheeler A. Ventilation with lower tidal volumes as compared with traditional tidal volumes for acute respiratory distress syndrome. N Engl J Med 2000;342:1301-8.

3. Determann RM, Royakkers A, Wolthuis EK, Vlaar AP, Choi G, Paulus F, et al. Ventilation with lover tidal volumes as compared with conventional tidal volumes for patients without acute lung injury: A preventive randomized controlled trial. Crit Care 2010;14:R1

4. Neto AS, Simonis FD, Barbas CS, Biehl M, Determann RM, Elmer J, et al. LungProtective ventilation with low tidal volumes and occurrance of pulmonary complications in patients without acute respitory distress syndrome: A systematic review and individual patient data meta-analysis. Crit Care Med 2015;43:2155-63.

5. Gajic O, Dara SI, Mendez JL, Adesanya $A O$, Festic E, Caples SM, et al. Ventilator- associated lung injury in patients without acute lung injury at the onset of mechanical ventilation. Crit Care Med 2004;32:1817-24

6. Futier E, Constantin JM, Paugam-Burtz C, Pascal J, Eurin M, Neuschwander A, et al. A trial of intraoperative low-tidalvolume ventilation in abdominal surgery. N Engl J Med 2013;369:428-37.

7. Karalapillai D, Weinberg L, Galtieri J, Glassford N, Eastwood G, Darvall J, et al. Current ventilationpractice during general anaesthesia: A prospective audit in Melbourne, Australia. BMC Anesthesiology 2014;14;85.

8. Jaber $\mathrm{S}$, Coisel $\mathrm{Y}$, Chanques G, Futier F, Constantin JM, Michelet JM, et al. A multicentre observational study of intraoperative ventilatory management during general anesthesia:tidal volumes and relation to body weight. Anesthesia 2012;67:999-1008.

9. www.ardsnet.org/files/ pbwtables_2005-02-02.pdf (Erişim tarihi: 28/11/2018)

10. Neto AS, Cardoso SO, Manetta JA, Parreira VG, Esposito DC, Pasquallucci Mde $\mathrm{O}$, et al. Association between use of lung-protective ventilation with lower tidal volumes and clinical outcomes among patients without acute respiratory distress syndrome: a meta-analysis. JAMA 2012; 308:1651-9.

11. Neto AS, Barbas CS, Simonis FD, ArtigasRaventos A, Canet J, Determann RM, et al. Epidemiological characteristics, practice of ventilation, and outcome in patients at risk of acute respiratory distress sydrome in intensive care units from 16 countries (PRoVENT): an international, multicentre, prospective study. Lancet Respir Med 2016;4:88293.

12. Alencar R, D'Angelo V, Carmona R, Shultz JM. Patients with uninjured lungs may also benefit from lungprotective ventilator settings. F1000Res 2017;6:2040

13. Pronovost PJ. Enhancing physicians use of clinical guidelines. JAMA 2013;310:2501-2.

14. Bourdeaux CP, Thomas MJ, Gould TH, Malhotra G, Jarvstad A, Jones $T$, et al. Increasing compliance with low tidal volume ventilation in the ICU with two nudge-based interventions: evaluation through intervention time-series analyses. BMJ Open 2016;6:e010129. 